\title{
Combined effects of cigarette smoking, gene polymorphisms and methylations of tumor suppressor genes on non small cell lung cancer: a hospital-based case-control study in China
}

\author{
Yongtang $\mathrm{Jin}^{1 *}$, Heyun $\mathrm{Xu}^{2}$, Chunye zhang ${ }^{1}$, Yunming Kong ${ }^{3}$, Yong $\mathrm{Hou}^{3}$, Yingchun $\mathrm{Xu}^{4}$, Shaoli Xue ${ }^{5}$
}

\begin{abstract}
Background: Cigarette smoking is the most established risk factor, and genetic variants and/or gene promoter methylations are also considered to play an essential role in development of lung cancer, but the pathogenesis of lung cancer is still unclear.

Methods: We collected the data of 150 cases and 150 age-matched and sex-matched controls on a Hospital-Based Case-Control Study in China. Face to face interviews were conducted using a standardized questionnaire. Gene polymorphism and methylation status were measured by RFLP-PCR and MSP, respectively. Logistic regressive model was used to estimate the odds ratios (OR) for different levels of exposure.

Results: After adjusted age and other potential confounding factors, smoking was still main risk factor and significantly increased 3.70-fold greater risk of NSCLC as compared with nonsmokers, and the ORs across increasing levels of pack years were 1, 3.54, 3.65 and 7.76, which the general dose-response trend was confirmed. Our striking findings were that the risk increased 5.16, 8.28 and 4.10-fold, respectively, for NSCLC with promoter hypermethylation of the 16, DAPK or RAR $\beta$ gene in smokers with CYP1A1 variants, and the higher risk significantly increased in smokers with null GSTM1 and the OR was 17.84 for NSCLC with p16 promoter hypermethylation, 17.41 for DAPK, and 8.18 for RARB in smokers with null GSTM1 compared with controls (all $p<0.01$ ).

Conclusion: Our study suggests the strong combined effects of cigarette smoke, CYP1A1 and GSTM1 Polymorphisms, hypermethylations of $p 16, D A P K$ and RAR $\beta$ promoters in NSCLC, implying complex pathogenesis of NSCLC should be given top priority in future research.
\end{abstract}

\section{Background}

Lung cancer kills over one million people each year all over the world, and it is a major public health problem as the leading cause of cancer death in men and second leading cause in women [1]. The two major forms of lung cancer are non-small cell lung cancer (NSCLC, about $85 \%$ of all lung cancer) which includes squamous cell carcinoma, adenocarcinoma and large cell carcinoma, and small-cell lung cancer (SCLC, about 15\%)[2]. Lung cancer mortality has increased rapidly during

\footnotetext{
* Correspondence: jinedu@zju.edu.cn

'Department of Environmental Medicine or Institute of Environmental Medicine, Zhejiang University School of Medicine, Zhejiang University, 310058 Hangzhou, China

Full list of author information is available at the end of the article
}

recent years in Asian countries as the use of tobacco products is increasing [3]. About $80-90 \%$ of lung cancers are attributable to cigarette smoking, and an estimated $20 \%$ of all lung cancers are caused by a combination of environmental and/or genetic factors [4], but inter-individual differences in carcinogen metabolism may play an essential role in the initiation and progression of this environmental cancer and affect individual susceptibility to lung cancer $[5,6]$. Cigarette tobacco contains a variety of carcinogens, such as polycyclic aromatic hydrocarbons(PAHs), N-nitrosoamines, and aromatic heterocyclic amines [7]. PAHs are metabolized to reactive DNA binding diols epoxides by phase I (e.g. CYP1A1) and detoxified by phase II (e.g. GSTM1) before targeting 
DNA. It is possible that individual variations in metabolic activities in each phase or both phases of metabolism coordinately modulate the clearance of DNA [8]. Many studies have reported that polymorphism in CYP1A1 as well as in GSTM1, or combination effect of both, have been associated with different types of cancer risk including human lung cancer [9].

It is now recognized that not only genetic mechanisms, such as gross chromosomal alterations or single nucleotide mutations, but also aberrant DNA methylation provides one or both of the two hits postulated in Knudson's two hit hypothesis for the inactivation of tumor suppressor genes. Many studies have indicated that aberrant methylation of the promoter causes transcriptional silencing of some important suppressor genes, such as cell cycle gene $p 16$, apoptosis gene $D A P K$, cell differentiation and proliferation gene $R A R \beta$, DNA repair gene $M G M T$, and this has been implicated in the carcinogenic process in human lung cancer [4]. Furthermore, methylation has been described as an early event in lung tumorigenesis and variation in methylation status has been associated with cigarette smoke exposure $[10,11]$. In addition, only a relative small study has examined the relationship between polymorphisms in XRCC1, GSTM1, GSTP1, NQO1, and MPO and aberrant methylation of $p 16, R A R \beta$ and $M G M T$ in lung cancer [6]. Those result suggested that GSTP1 and NQO1 variations increased the risk of $M G M T$ methylation, and the possibility of $p 16$ and $R A R \beta$ methylations was increased for $X R C C 1$ and $M P O$ gene polymorphisms, indicating the interactions between gene polymorphisms and aberrant methylation of tumor suppress genes.

Above facts led us hypothesize that major metabolic enzyme gene genetic polymorphisms and environmental factors, such as cigarette smoking and diet habits, may interact during the hypermethylations of tumor suppressor gene (TSG) promoters in the carcinogenesis of NSCLC. So, the present study have mainly investigated the association between cigarette smoking, polymorphisms of CYP1A1 and GSTM1 genes, hypermethylations of $p 16, D A P K$ and $R A R \beta$ gene promoters in NSCLC.

\section{Methods}

\section{Study population}

150 individuals with NSCLC and 150 age-matched (within 3 years) and sex-matched controls were enrolled in this study from June 2005 to December 2007 at $1^{\text {st }}$ Affiliated hospital of Anhui Medical University, China. Of patients with lung cancer, histological subtype including 83 squamous cell carcinomas, 33 adenocarcinomas and 34 mixed types of both were confirmed. 57 patients had stage I disease, 64 patients had stage II disease, 20 patients had stage III A disease, 5 patients had stage III $\mathrm{B}$ disease, and 4 patients had stage IV disease. Controls were selected from patients newly diagnosed with diseases other than cancer and chronic respiratory diseases or from individuals receiving routine medical examinations at the same hospitals. There were no significant difference of mean age between cases and controls $(59.81 \pm 9.18$ vs $59.91 \pm 8.71$ years $)$. There were 125 males and 25 females in cases or controls group. This study was approved by the Ethical Committee of Anhui Medical University and conducted in accordance with the recommendations outlined in the Declaration of Helsinki, and all subjects provided written informed consent.

\section{Exposure to environmental factors}

Trained interviewers used a structured questionnaire to interview each subject face to face when the subjects agreed to take part in this study and underwent medical examination. The questionnaire mainly included questions on demographic factors, smoking history (duration and daily consumption of cigarettes), consumption of alcohol, tea drinking and dietary factors (i.e. intake of peppery and/or fruit), family history of cancer in first relatives (i.e., parents, siblings and offspring), and clinical features of lung cancer and complete medical history. Smoking habit was defined as smoking more than 1 cigarette a day for at least 1 year, or more than 360 cigarettes a year. Pack years were calculated by multiplying the number of packs of cigarettes smoked a day by the number of years the person had smoked. Alcohol habit was defined as drinking more than twice a week, consumption of more than $50 \mathrm{ml}$ of heavy liquor or 500 $\mathrm{ml}$ of beer on each occasion. Tea habit was defined as drinking tea at least one time a day for at least 1 year. The servings of peppery or fruit was defined to intake more than twice a week.

\section{DNA extraction and genotyping}

Cases and controls were asked to provide $5 \mathrm{ml}$ peripheral venous blood. This was separated in two aliquots of $1 \mathrm{ml}$ serum and in two aliquots of buffy coats and stored at $-20^{\circ} \mathrm{C}$. Genomic DNA was extracted from the buffy coats using QIA Gen Blood Kit according to the manufacture's instructions (Qiagen). A DyNA Quant 200 fluormeter (Hoefer, San Francisco, CA) was used to test DNA concentration. CYP1A1 (MspI) polymorphism and GSTM1 deletion were measured by RFLP-PCR on ABI 9600 Thermal Cycler. Table 1 showed the main parameters of PCR.

\section{Methylaiton-specific PCR for p16, DAPK and RAR $\beta$ promoters}

Primary tumor and corresponding nonmalignant lung tissue samples ( $\mathrm{n}=150$, separately) were obtained from NSCLC patients who had been treated with curative 
Table 1 Summary of primer sequences, annealing temperatures and PCR product sizes used for CYP1A1 (Mspl) and GSTM1

\begin{tabular}{llll}
\hline Gene & Primer & ${ }^{\circ} \mathbf{C}$ & bp \\
\hline CYP1A1 (Mspl) & Forward 5'-CAGTGAAGAGGTGTAGCCGCT-3' & 60 & 340 \\
& Reverse 5'-TAGGAGTCTTGTCTCATGCCT-3' & 59 & \\
GSTM1 & Forward 5'-GAACTCCCTGAAAAGCTAAAGC-3' & \\
& Reverse 5'-GTTGGGCTCAAATATACGGTG G-3' & 59 & 215 \\
$\beta$-Globin (reference) & Forward 5'-CAACTTCATCCACGTCACC-3' & \\
& Reverse 5'-GAAGAGCCAAGGACAGGTA-3' & \\
\hline
\end{tabular}

resectional surgery in $1^{\text {st }}$ Affiliated hospital of Anhui Medical University between June 2005 and December 2007. Those samples were snap-frozen in liquid nitrogen and stored at $-70^{\circ} \mathrm{C}$ until genomic DNA preparation. Genomic DNA was extracted using QIA tissue kitaccording to the manufacturer's instructions (Qiagen). A DyNA Quant 200 fluorometer (Hoefer, San Francisco, CA) was used to measure DNA concentration.

Methylation status of the promoter region of the $p 16$, $D A P K$ and/or $R A R \beta$ was determined by MSP described by Zochbauer-Muller et al. [12]. Two sets of primers were designed, one specific for DNA methylated at the promoter region of each gene and the other specific for unmethylated DNA (Table 2). Amplification was carried out on ABI 9600 Thermal Cycler.

\section{Data analysis}

To determine the association between each of the test genes and lung cancer, the homozygous (AA or aa genotype) and heterozygous (Aa genotype) states of the variants were first analyzed as categorical variables, and then reanalyzed as dichotomized variables grouped by the risk genotype (i.e., 0 for the wild type homozygous, and 1 for the other genotypes combined). To evaluate the effects of combined genotypes, environmental factors either together or separately, subjects were categorized into homozygous wild type, and possession of one or more of the risk genotypes (heterozygous + homozygous for the variant). Compared with the wild type genotype, the odds ratio (OR) and 95\% confidence interval (CI) of the various genotypes was calculated for lung cancer risks in univariate analysis model. Multivariate logistic regression was conducted to estimate the relationship between smoking, polymorphisms of metabolic enzyme genes and methylation inactivate of tumor suppressor genes in NSCLC after adjusted the potential confound factors. SAS software (version 9.1; SAS Institute, Inc.) was used for statistical analysis, using the $x^{2}$ and Fisher's exact test for differences between groups and $t$ tests between means. All tests were two-sided, and a $p$ value of $<0.05$ for any test or models was considered statistically significant.

\section{Results}

The ORs of major risk factors among cased and controls are shown in Table 3. After adjusting for potential confounders, there were no significant differences between the cases and controls in alcohol habit, tea habit, dust exposure ( $\geq 1$ month/year), toxin exposure ( $\geq 1$ month/ year), and the family history of lung cancer among first relatives of patients. Genotype frequencies for CYP1A1 and GSTM1 are calculated, which these distributions are consistent with the Hardy-Weinberg equilibrium model. In the control group, the allele frequency for MspI was 0.30 (a), whereas that for lung cancer group was 0.29. A non-significant difference was observed between cases and controls. In addition, 53\% of controls and 63\% of cases were homozygous for null variant allele of GSTM1. No significant associations between the variants of CYP1A1 or GSTM1 and lung cancer. However, significant associations were also found between lung cancer and the follow variables: smoking habit, pack years, peppery (servings, $>2$ times/week), and fruit (servings, $>2$ times/week) (Table 3).

Table 2 Summary of primer sequences*, annealing temperatures, and PCR product sizes used for MSP

\begin{tabular}{|c|c|c|c|c|}
\hline Gene & Forward primer $\left(5^{\prime}-3^{\prime}\right)$ & Reverse primer $\left(3^{\prime}-5^{\prime}\right)$ & $\operatorname{Tm}\left({ }^{\circ} \mathrm{C}\right)$ & Size (bp) \\
\hline \multirow[t]{2}{*}{ p16 } & M: TTATTAGAGGGTGGGGCGGATCGC** & M: GACCCCGAACCGCGACCGTAA & 60 & 150 \\
\hline & U: TTATTAGAGGGTGGGGTGGATTGT & U: CAACCCCAAACCACAACCATAA & 60 & 151 \\
\hline \multirow[t]{2}{*}{ DAPK } & M: GGATAGTCGGATCGAGTTAACGTC & M: CCCTCCCAAACGCCGA & 59 & 98 \\
\hline & U: GGAGGATAGTTGGATTGAGTTAATGTT & U: CAAATCCCTCCCAAACACCAA & 59 & 106 \\
\hline \multirow[t]{2}{*}{$R A R \beta$} & M: TCGAGAACGCGAGCGATTCG & M: GACCAATCCAACCGAAACGA & 56 & 146 \\
\hline & U: TTGAGAATGTGAGTGATTTGA & U: AACCAATCCAACCAAAACAA & 56 & 146 \\
\hline
\end{tabular}

* Reference for primer sequences: Ref. [13].

** M. methylated-specific primers: $U$. unmethylated-specific primers. 
Table 3 ORs of major risk factors for non-small cell lung cancer.

\begin{tabular}{|c|c|c|c|c|c|c|}
\hline \multirow[t]{2}{*}{ Factor } & \multicolumn{3}{|c|}{ Crude risk } & \multicolumn{3}{|c|}{ Adjusted risk } \\
\hline & $\overline{O R}$ & $95 \% \mathrm{Cl}$ & p-value & $\mathrm{OR}^{\mathrm{a}}$ & $95 \% \mathrm{Cl}$ & p-value \\
\hline Smoking habit(yes/no) & 2.21 & $1.35-3.3 .63$ & $<0.01$ & 3.70 & $1.49-9.19$ & $p<0.01$ \\
\hline Pack years $<20$ & 1.00 & - & - & 1.00 & - & - \\
\hline 20-30 & 3.27 & $1.43-7.49$ & $<0.01$ & 3.54 & $1.11-11.26$ & $p<0.05$ \\
\hline $30-40$ & 3.53 & $1.72-7.26$ & $<0.01$ & 3.65 & $1.27-10.50$ & $p<0.05$ \\
\hline$\geq 40$ & 7.54 & $3.95-14.41$ & $<0.01$ & 7.76 & $3.00-20.11$ & $p<0.01$ \\
\hline$x^{2}$ test for trend & \multicolumn{3}{|c|}{$p<0.001$} & \multicolumn{3}{|c|}{$p<0.001$} \\
\hline Alcohol habit(yes/no) & 1.46 & $0.92-2.30$ & $>0.05$ & 1.72 & $0.83-3.53$ & $p>0.05$ \\
\hline Tea habit(yes/no) & 1.14 & $0.69-1.89$ & $>0.05$ & 0.92 & $0.41-2.09$ & $p>0.05$ \\
\hline Peppery (servings, > 2 times/week, yes/no) & 0.61 & $0.38-0.98$ & $<0.05$ & 0.35 & $0.16-0.76$ & $p<0.01$ \\
\hline Fruit (servings, $>2$ times/week, yes/no) & 0.28 & $0.14-0.58$ & $<0.01$ & 0.16 & $0.06-0.43$ & $p<0.01$ \\
\hline Dust exposure (yes/no) & 3.55 & $2.08-6.04$ & $<0.01$ & 2.06 & $0.93-4.57$ & $p>0.05$ \\
\hline Toxin exposure (yes/no) & 1.31 & $0.79-2.18$ & $>0.05$ & 0.68 & $0.30-1.56$ & $p>0.05$ \\
\hline Lung cancer in firstdegree relatives (yes/no) & 1.35 & $0.63-2.88$ & $>0.05$ & 1.44 & $0.41-5.06$ & $p>0.05$ \\
\hline $\operatorname{CYP1A1}((\mathrm{Aa}+\mathrm{aa}) / \mathrm{AA})^{c}$ & 1.03 & $0.65-1.62$ & $>0.05$ & 0.83 & $0.42-1.65$ & $p>0.05$ \\
\hline GSTM1 (null/power) $^{d}$ & 1.55 & $0.98-2.46$ & $>0.05$ & 1.13 & $0.57-2.24$ & $p>0.05$ \\
\hline
\end{tabular}

${ }^{a}$ adjusted for sex, age, alcohol habit, tea habit, smoking habit and history of lung cancer in first-degree relatives.

${ }^{b}$ cumulative exposure $\geq 3$ months/year or continuous exposure $\geq 1$ months/year.

${ }^{c} \mathrm{AA}=$ homogeneity wild genotype, $\mathrm{Aa}=$ heterogeneity genotype, aa = homogeneity variant genotype

d - = null type, $+=$ power

This study confirmed smoking was the main risk factor of lung cancer, and increased 3.70 times greater risk of NSCLC compared with nonsmoker. Further, the OR of NSCLC increased with higher categories of total smoking pack year, from 3.54 in the second category to 7.76 in the fourth category (Table 3). ORs of the three higher categories were all statistically significant. After adjustment for the potential confounding factors in the multivariate analysis models, ORs in each category of smoking pack years increased, and CIs became wider, but the general dose-response trend was maintained (Table 3). Interestingly, we found the preventive effects of peppery or fruit servings on lung cancer, and OR was 0.35 (95\%CI, 0.16-0.76) and 0.16 (95\%CI, 0.06-0.43), respectively. This study suggested non-significant association of variants of CYP1A1 and GSTM1 with NSCLC alone or in combination. However, the risk increased about 4-fold in smokers with CYP1A1 variants as compared with $C Y P 1 A 1$ wild homozygous non-smokers and 7-fold when smokers having null GSTM1 were compared with power GSTM1 non-smokers. These results can imply the interactions of smoking and the genetic variants of CYP1A1 and GSTM1 in NSCLC (Table 4).

We used MSP to determine the frequency of methylation of $p 16, D A P K$ and $R A R \beta$ in 150 resected NSCLCs, which was $48.67 \%, 58.67 \%$ and $60.00 \%$, respectively. In the corresponding nonmalignant lung tissues, it was seen at low frequencies for $p 16$ (9.93\%), DAPK $(9.93 \%)$ and $R A R \beta$ (17.02\%). Those indicated the significant difference between lung cancer tissues and nonmalignant lung tissue in methylations of three genes. In addition, we found that at least one of these three genes had methylation in $85.33 \%$ of the tumors; $26 \%$ of the tumors had only one gene methylated, $36.67 \%$ of the tumors had two genes methylated and $22.67 \%$ of the tumors had three genes methylated. A statistically significant corrrlation was found for the methylation status between $p 16$ and DAPK ( $\mathrm{p}=0.0006$ ), whereas the methylation status of the other genes was independent when compared with each other. Although no association was apparent among the CYP1A1 or GSTM1 polymorphisms and $p 16, D A P K$ or $R A R \beta$ promoter methylation, GSTM1 null genotype was significantly associated with at least one methylation among $p 16, D A P K$ and $R A R \beta$ genes (OR, 1.67; 95\% CI, 1.01-2.77) (no data shown).

Table 5 presents OR estimates for smoking habits, pack years, diet habits, family history of lung cancer, and polymorphisms of CYP1A1 and GSTM1 as compared with controls according to the cases with or without promoter hypermethylation of the $p 16, D A P K$ or $R A R \beta$ gene. Obviously, smoking habits increased the risk of NSCLC with promoter hypermethylation of the $p 16, D A P K$ or $R A R \beta$, which OR is $4.56,3.83,3.11$, respectively. As the amount of pack years increased, the risk of NSCLC with promoter hypermethylation of the $p 16, D A P K$ or $R A R \beta$ gene was greater, indicating a graded positive association between both. The results may also imply the interaction between cigarette smoking and promoter hypermethylation of the $p 16, D A P K$ or $R A R \beta$ gene in NSCLC. In addition, a possible association was found between null GSTM1 and NSCLC with promoter hypermethylation of the DAPK or RAR $\beta$ gene, 
Table 4 The interactions of smoking, CYP1A1 and GSTM1 variants in non-small cell lung cancer

\begin{tabular}{|c|c|c|c|c|c|}
\hline \multicolumn{2}{|c|}{ Factor } & \multirow[t]{2}{*}{ Case(n) } & \multirow[t]{2}{*}{ Control(n) } & \multirow[t]{2}{*}{ Crude OR $(95 \% \mathrm{Cl})$} & \multirow[t]{2}{*}{ Adjusted $\mathrm{OR}^{\mathrm{a}}(95 \% \mathrm{Cl})$} \\
\hline CYP1A1 ${ }^{\mathrm{b}}$ & GSTM1 $^{c}$ & & & & \\
\hline \multirow[t]{2}{*}{$\mathrm{Aa}+\mathrm{aa}$} & - & 43 & 39 & $1.63(0.81-3.31)$ & $1.67(0.85-3.29)$ \\
\hline & + & 28 & 31 & $1.34(0.62-2.89)$ & $1.55(0.74-3.25)$ \\
\hline \multirow[t]{2}{*}{ AA } & - & 52 & 40 & $1.93(0.97-3.84)$ & $2.03(1.04-3.94)^{*}$ \\
\hline & + & 27 & 40 & 1.00(reference) & 1.00(reference) \\
\hline Smoking habit & CYPIA1 & & & & \\
\hline \multirow[t]{2}{*}{ Yes } & $\mathrm{Aa}+\mathrm{aa}$ & 52 & 39 & $2.37(1.10-5.15)^{*}$ & $3.72(1.56-8.86)^{* *}$ \\
\hline & AA & 61 & 48 & $2.26(1.07-4.78)^{*}$ & $3.47(1.47-8.16)^{* *}$ \\
\hline \multirow[t]{2}{*}{ No } & $\mathrm{Aa}+\mathrm{aa}$ & 19 & 31 & $1.09(0.45-2.66)$ & $1.08(0.47-2.51)$ \\
\hline & $\mathrm{AA}$ & 18 & 32 & 1.00(reference) & 1.00(reference) \\
\hline Smoking habit & GSTM1 & & & & \\
\hline \multirow[t]{2}{*}{ Yes } & - & 70 & 51 & $4.00(1.79-9.09)^{* *}$ & $6.76(2.62-17.46)^{* *}$ \\
\hline & + & 43 & 36 & $3.48(1.48-8.33)^{* *}$ & $5.93(2.26-15.59)^{* *}$ \\
\hline \multirow[t]{2}{*}{ No } & - & 25 & 28 & $2.60(1.03-6.67)^{*}$ & $2.84(1.17-6.92)^{*}$ \\
\hline & + & 12 & 35 & 1.00(reference) & 1.00(reference) \\
\hline
\end{tabular}

a adjusted for sex, age, alcohol habit, tea habit, smoking habit and history of lung cancer in first-degree relatives.

${ }^{\mathrm{b}} \mathrm{AA}=$ homogeneity wild genotype, $\mathrm{Aa}=$ heterogeneity genotype, aa = homogeneity variant genotype

c - = null type, $+=$ power

* $p<0.05 * * p<0.01$

Table 5 The interactions between cigarette smoking, genetic variants of CYP1A1and GSTM1, and promoter hypermethylations of the $p 16, D A P K$ and $R A R \beta$ genes in non-small cell lung cancer

\begin{tabular}{|c|c|c|c|c|c|c|}
\hline \multirow[t]{3}{*}{ Factor } & \multicolumn{6}{|c|}{$\mathrm{OR}^{\mathrm{a}}(95 \% \mathrm{Cl})$} \\
\hline & \multicolumn{3}{|c|}{ Cases with TSG $^{\text {b }}$ promoter hypermethylation } & \multicolumn{3}{|c|}{ Cases without TSG promoter hypermethylation } \\
\hline & p16 & DAPK & RAR $\beta$ & p16 & DAPK & RAR $\beta$ \\
\hline \multirow[t]{2}{*}{ Smoking habit (yes/no) } & $4.56^{* *}$ & $3.83^{* *}$ & $3.11^{* *}$ & 1.34 & 1.23 & 1.45 \\
\hline & $(2.17-9.58)$ & $(1.99-7.38)$ & $(1.67-5.78)$ & $(0.76-2.37)$ & $(0.67-2.26)$ & $(0.77-2.71)$ \\
\hline \multicolumn{7}{|l|}{ Pack years } \\
\hline \multirow[t]{2}{*}{$<20$} & 1.00 & 1.00 & 1.00 & 1.00 & 1.00 & 1.00 \\
\hline & (reference) & (reference) & (reference) & (reference) & (reference) & (reference) \\
\hline \multirow[t]{2}{*}{$20-29$} & $4.62^{* *}$ & $6.72^{* *}$ & $3.27^{*}$ & 2.60 & 1.23 & $3.27^{*}$ \\
\hline & $(1.63-13.13)$ & $(2.63-17.18)$ & $(1.23-8.69)$ & $(0.99-6.80)$ & $(0.37-4.12)$ & $(1.19-9.01)$ \\
\hline \multirow[t]{2}{*}{$30-39$} & $5.08^{* *}$ & $6.82^{* *}$ & $4.27^{* *}$ & $1.75^{*}$ & 1.58 & $2.70^{*}$ \\
\hline & $(2.04-12.69)$ & $(2.2 .94-15.81)$ & $(1.88-9.70)$ & $(1.19-6.36)$ & $(0.59-4.20)$ & $(1.06-6.89)$ \\
\hline \multirow[t]{2}{*}{$\geq 40$} & $14.29^{* *}$ & $13.50^{* *}$ & $9.50^{* *}$ & $4.17^{* *}$ & $4.01^{* *}$ & $5.34^{* *}$ \\
\hline & $(6.55-31.18)$ & $(6.31-28.89)$ & $(4.62-19.53)$ & $(1.96-8.88)$ & $(1.85-8.68)$ & (2.40-11.88) \\
\hline$x^{2}$ test for trend & $p<0.001$ & $p<0.001$ & $p<0.001$ & $p<0.001$ & $p<0.001$ & $p<0.001$ \\
\hline \multirow[t]{2}{*}{ CYP1A1 $((\mathrm{Aa}+\mathrm{a} a) / \mathrm{AA})^{c}$} & 0.97 & 1.14 & 1.06 & 1.07 & 0.88 & 0.94 \\
\hline & $(0.55-1.81)$ & $(0.67-1.92)$ & $(0.62-1.80)$ & $(0.61-1.86)$ & $(0.48-1.59)$ & $(0.51-1.71)$ \\
\hline \multirow[t]{2}{*}{ GSTM1 (null/power) ${ }^{d}$} & 1.45 & $1.73^{*}$ & $1.98^{* *}$ & 1.67 & 1.33 & 1.10 \\
\hline & $(0.82-2.56)$ & $(1.01-2.99)$ & $(1.15-3.44)$ & $(0.96-2.94)$ & $(0.73-2.43)$ & $(0.60-2.00)$ \\
\hline
\end{tabular}

a adjusted for sex, age, alcohol habit, tea habit, smoking habit and history of lung cancer in first-degree relatives.

${ }^{\mathrm{b}}$ TSG $=$ tumor suppress gene including $p 16, D A P K$ and $R A R \beta$.

${ }^{c} \mathrm{AA}=$ homogeneity wild genotype, $\mathrm{Aa}=$ heterogeneity genotype, aa = homogeneity variant genotype

d - = null type, $+=$ power

${ }^{*} p<0.05$, ** $p<0.01$ 
implying effect of GSTM1 polymorphism on the aberrant methylations of TSG in lung cancer. Of note, higher consumption of fruit was associated with lower risk of NSCLC with or without promoter hypermethylation of the $p 16, D A P K$ or $R A R \beta$ gene (no data shown) (Table 5).

Based on above results, Table 6 considers the interaction between smoking habits, polymorphisms of CYP1A1 and GSTM1 variants in NSCLC with or without promoter hypermethylations of the $p 16, D A P K$ or $R A R \beta$ gene as compared with controls. We didn't found the interaction between CYP1A1 polymorphisms and GSTM1 variant in NSCLC with or without promoter hypermethylation of the $p 16, D A P K$ or $R A R \beta$ gene. Nevertheless, as compared with controls, the risk increased 5.16, 8.28 and 4.10-fold, respectively, for NSCLC with promoter hypermethylation of the $p 16$, $D A P K$ or $R A R \beta$ gene in smokers with $C Y P 1 A 1$ variants $(\mathrm{Aa}+\mathrm{aa})$. Strikingly, the risk strongly increased in smokers with null GSTM1, and the OR was 17.84 for NSCLC with $p 16$ promoter hypermethylation, 17.41 for $D A P K$, and 8.18 for $R A R \beta$ in smokers with null GSTM1 compared with controls. In contrast, the smokers with null GSTM1 have lower risk for NSCLC without TSG promoter hypermethylation. To a certain extent, these results are in agreement with a previous multiplicative model for risk combination between smoking habits and metabolic enzyme gene polymorphisms analyzed when the cases were not stratified by TSG methylation status. These results may further confirm the interactions

Table 6 Interactions between cigarette smoking and the genetic variants of CYP1A1 and GSTM1 in non-small cell lung cancer with or without promoter hypermethylations of the $p 16, D A P K$ and $R A R \beta$ genes

\begin{tabular}{|c|c|c|c|c|c|c|c|}
\hline \multicolumn{2}{|c|}{ Factor } & \multicolumn{6}{|c|}{$\mathrm{OR}^{\mathrm{a}}(95 \% \mathrm{Cl})$} \\
\hline & & \multicolumn{3}{|c|}{ Cases with TSG $^{\text {b }}$ promoter hypermethylation } & \multicolumn{3}{|c|}{ Cases without TSG promoter hypermethylation } \\
\hline & & p16 & DAPK & RAR $\beta$ & p16 & DAPK & RAR $\beta$ \\
\hline$C Y P 1 A 1^{C}$ & GSTM1 $^{\mathrm{d}}$ & & & & & & \\
\hline \multirow[t]{4}{*}{ Aa+aa } & - & 1.41 & 2.05 & $2.12^{*}$ & 1.96 & 1.18 & 1.03 \\
\hline & & $(0.64-3.08)$ & $(0.94-4.47)$ & $(0.99-4.52)$ & $(0.84-4.59)$ & $(0.50-2.81)$ & $(0.41-2.56)$ \\
\hline & + & 0.97 & 1.48 & 1.12 & 1.88 & 1.19 & 1.61 \\
\hline & & $(0.40-2.34)$ & $(0.63-3.47)$ & $(0.47-2.69)$ & $(0.76-4.61)$ & $(0.48-2.97)$ & $(0.66-3.94)$ \\
\hline \multirow[t]{4}{*}{ AA } & - & 1.44 & $2.14^{*}$ & 2.07 & $2.64^{*}$ & 1.69 & 1.75 \\
\hline & & $(0.66-3.12)$ & $(0.99-4.63)$ & $(0.97-4.40)$ & $(1.16-5.99)$ & $(0.75-3.82)$ & $(0.76-4.03)$ \\
\hline & + & 1.00 & 1.00 & 1.00 & 1.00 & 1.00 & 1.00 \\
\hline & & (reference) & (reference) & (reference) & (reference) & (reference) & (reference) \\
\hline Smoking habit & CYP1A1 & & & & & & \\
\hline \multirow[t]{4}{*}{ Yes } & Aa+aa & $5.16^{*}$ & $8.28^{* *}$ & $4.10^{* *}$ & 2.73 & 1.58 & 2.82 \\
\hline & & $(1.45-18.35)$ & $(2.38-28.75)$ & $(1.43-11.76)$ & $(0.97-7.64)$ & $(0.54-4.68)$ & $(0.87-9.16)$ \\
\hline & $\mathrm{AA}$ & $4.75^{*}$ & $6.57^{* *}$ & $3.50^{*}$ & 2.60 & 2.16 & 3.29 \\
\hline & & $(1.35-16.65)$ & $(1.91-22.64)$ & $(1.22-10.01)$ & $(0.95-7.11)$ & $(0.77-6.02)$ & $(1.07-10.11)$ \\
\hline \multirow[t]{4}{*}{ No } & Aa+aa & 0.94 & 0.85 & 0.91 & 1.20 & 1.39 & 1.38 \\
\hline & & $(0.24-3.68)$ & $(0.25-2.88)$ & $(0.31-2.70)$ & $(0.47-3.08)$ & $(0.52-3.72)$ & $(0.48-3.96)$ \\
\hline & AA & 1.00 & 1.00 & 1.00 & 1.00 & 1.00 & 1.00 \\
\hline & & (reference) & (reference) & (reference) & (reference) & (reference) & (reference) \\
\hline Smoking habit & GSTM1 & & & & & & \\
\hline \multirow[t]{4}{*}{ Yes } & - & $17.84^{* *}$ & $17.41^{* *}$ & $8.18^{* *}$ & $4.43^{* *}$ & 2.76 & $4.69^{*}$ \\
\hline & & $(3.10-102.64)$ & $(4.21-72.05)$ & $(2.53-26.49)$ & $(1.54-12.78)$ & $(0.88-8.60)$ & $(1.29-17.05)$ \\
\hline & + & $17.62^{* *}$ & $12.29^{* *}$ & $5.14^{* *}$ & $3.09 *$ & $3.35^{*}$ & $7.10^{* *}$ \\
\hline & & $(3.08-100.91)$ & $(2.95-51.21)$ & $(1.55-17.05)$ & $(1.04-9.14)$ & $(1.08-10.39)$ & $(1.98-25.41)$ \\
\hline \multirow[t]{4}{*}{ No } & - & $6.18^{* *}$ & 2.81 & 2.47 & 2.24 & $3.00^{*}$ & $3.68^{*}$ \\
\hline & & $(1.14-33.56)$ & $(0.77-10.20)$ & $(0.79-7.72)$ & $(0.85-2.90)$ & $(1.05-8.55)$ & $(1.15-11.77)$ \\
\hline & + & 1.00 & 1.00 & 1.00 & 1.00 & 1.00 & 1.00 \\
\hline & & (reference) & (reference) & (reference) & (reference) & (reference) & (reference) \\
\hline
\end{tabular}

\footnotetext{
a adjusted for sex, age, alcohol habit, tea habit, smoking habit and history of lung cancer in first-degree relatives.

${ }^{\mathrm{b}}$ TSG $=$ tumor suppress gene including $p 16, D A P K$ and $R A R \beta$

${ }^{c} \mathrm{AA}=$ homogeneity wild genotype, $\mathrm{Aa}=$ heterogeneity genotype, aa = homogeneity variant genotype

d - = null type, $+=$ power

${ }^{*} \mathrm{p}<0.05$, ${ }^{* *} \mathrm{p}<0.01$
} 
between smoking, genetic variant of $C Y P 1 A 1$ and GSTM1, and promoter hypermethylation of the $p 16$, $D A P K$ or $R A R \beta$ gene in NSCLC (Table 6).

\section{Discussion}

Many epidemiologic studies have demonstrated cigarette smoking is the major risk factor of lung cancer [13-15], with a obvious dose-response relationship [16]. Our findings $(\mathrm{OR}=3.70, \mathrm{p}<0.01)$ supported these results unquestionably. There are more than 4000 chemical materials in cigarette smoking, and approximately 200 may be carcinogens, such as aromatic hydrocarbons, which have proved to cause lung carcinogenesis, and increasing mortality from lung cancer is closely associated with the consumption of tobacco [14]. Although the majority of lung cancer patients are smokers, only $10-15 \%$ of all smokers will develop the disease [17], indicating environmental or genetic determinants in disease initiation, promotion and progression. Since many carcinogens require metabolic activation via phase I enzymes to enable to react with cellular macromolecules or metabolic detoxification via phase II enzymes to enable to eliminate from body, inter-individual differences in carcinogen metabolism may play a key role in environmental cancers $[4,6]$. The most frequently studied phase I and II enzymes include CYP1A1 and GSTM1. Studies from Japanese populations first found an association between CYP1A1 and polymorphisms and risk of lung cancer, with reports of $>2$-fold increased risk [18]. In a pooled analysis using data from 22 studies, a significant 2.4-fold increased in risk was observed in individuals carrying the MspI variant [19]. In addition, GSTM1 occurs in the null form in $\sim 50 \%$ of the Caucasian population. One of the first meta-analyses showed a modest increase in lung cancer among carriers of the GSTM1null genotype (OR $=1.13,95 \% \mathrm{CI} 1.04-1.25)$ [20]. The most recent and large meta-analysis [9] of Chinese population found that lung cancer risk for $C Y P 1 A 1$ variant was 1.34 -fold (95\%CI 1.08-1.67, $\mathrm{p}=0.008$ ) compared with the wild-type homozygous genotype, and the risk for the GSTM1 null genotype was 1.54-fold (95\%CI $1.31-1.80, \mathrm{p}<0.001)$ as compared with the GSTM1 present genotype. A recent pooled analysis also suggested that genetic polymorphisms in CYP1A1 and GSTM1 are associated with lung cancer risk among Asian populations [3]. Few studies have researched gene-gene interactions in lung cancer. An early study from Japan [18] reported the combined effects of CYP1A1 MspI genotype and deficient GSTM1 in lung cancer $(\mathrm{OR}=16.00)$, but only at a low-dose level of cigarette smoking. Also, another analysis indicated a possible interaction between the CYP1A1*2A allele and GSTM1 deletion on lung cancer risk in Caucasians [21]. However, as other studies have reported conflicting results for $C Y P 1 A 1$ and
GSTM1 polymorphisms in lung cancer [4,6], our study found neither significant risk of lung cancer for CYP1A1 variants or GSTM1 null genotypes nor possible combination effects of CYP1A1 and GSTM1 polymorphisms in the development of lung cancer. The majority of epidemiological studies on the effects of low penetrant genes in cancer etiology have considered main effects single nucleotide polymorphisms, or gene-environment interactions and rarely gene-gene interactions, mainly duo to the lack of statistical power [22]. Most observed associations between cancer and low penetrant gene variants have been weak or very weak [21]. However, penetrance of a gene variant depends on events such as the interaction with external exposures, with the internal environment or with other factors (e.g., gene promoter methylation).

In the present study, the significant interaction between cigarette smoking and CY1A1 or GSTM1 variants is consistent with the results of previous pooled analysis that the stronger association between the CYP1A1 MspI or GSTM1 null and lung cancer was found among smokers [22], but a non significant elevated risk of interaction between GSTM1 null genotype and lung cancer was reported among Asian by Benhamou and co-workers [23]. Cigarette smoking is known to be causally related to BPDE-DNA adducts that is elevated in the lung tissue of smokers with GSTM1 null genotype, which was found to induce mutations in the hotspot codons of the p53 gene [3,24]. Thus, we speculated that the interaction between CYP1A1 or GSTM1 polymorphisms and lung cancer is related to polycyclic aromatic hydrocarbons exposure derived from smoking because polycyclic aromatic hydrocarbons are primarily metabolized by CYP1A1 and GSTM1. The greater effects observed among smokers support the smoking-related etiology of lung cancer in Chinese population.

It is now recognized that not only the inherited variation in DNA sequence (e.g. gene mutations) but also the epigenetic events, such as aberrant DNA methylatoin, both play an essential role in the origination and development of lung cancer. The most widely studied epigenetic event in relation to lung cancer included the promoter hypermethylation of $p 16, D A P K$ or $R A R \beta$ gene $[4,6]$. Our findings reported the percentage for $p 16$, $D A P K$ or $R A R \beta$ methylated was the $48.67 \%, 58.67 \%$ and $60.00 \%$ in the tumor tissues of patients with lung cancer, respectively. Those results were separately a little greater than other findings that $p 16$ is methylated in $\sim 25-41 \%$ of NSCLC, DAPK in $16-44 \%$ and RAR $\beta$ in $40-43 \%$ $[25,26]$, which the differences may mainly result from ethnic variants. The study examined the relationship between polymorphisms in CYP1A1 and GSTM1 and aberrant methylation of $p 16, D A P K$ and $R A R \beta$ in lung cancer. It is the first to found GSTM1 null was 
associated with at least one methylation of $p 16, D A P K$ and $R A R \beta$ gene promoters $(\mathrm{OR}=1.67,95 \% \mathrm{CI} 1.01$ $2.77)$, supporting interaction between metabolic enzyme gene polymorphisms and hypermethylation of tumor suppressor genes in development of NSCLC $[27,28]$. Also, data from our unconditional logistic models is the first to show that tobacco smoke play dominant roles in NSCLC with hypermethylation of $p 16, D A P K$ or $R A R \beta$ promoter, but not without hypermethylation of those gene promoters. As the amount of cigarette smoking increased, the risk of NSCLC with $p 16, D A P K$ or $R A R \beta$ promoter hypermethylation increased. To our knowledge, we have first reported the interactions between smoking and polymorphisms of CYP1A1 and GSTM1 gene were significantly modified by hypermethylation of $p 16, D A P K$ or $R A R \beta$ promoter in NSCLC, indicating the combined effects of smoking, CYP1A1, GSTM1, p16, $D A P K$ and $R A R \beta$ gene on development of NSCLC. The findings suggest that smoking related biological pathways leading to the development of lung cancer involve not only hypermethylations of $p 16, D A P K$ and $R A R \beta$ promoters but also genetic polymorphisms of $C Y P 1 A 1$ and GSTM1 genes. Although it is unclear that environmental factors underlie the targeting of specific gene promoters for hypermethylation, the characterization of gene-environment interaction and epigenetic influences in carcinogenesis is of great importance for preventive measures such as the setting of exposure threshold values, public health campaigns and chemopreventive approaches. Those all need to be further confirmed and thoroughly studied in different populations.

This study has some strengths and limitations. This is first study on the interaction between cigarette smoking and the polymorphisms of CYP1A1 or GSTM1 for NSCLC with hypermethylations of $p 16, D A P K$ and $R A R \beta$ promoters, which carefully controlled for important confounding factors. The selective bias was mostly controlled by the design of a hospital-based case-control study. As other case-control studies, this study raises concern about recall bias and residual confounding. Of course, the major difficult is still the inability to separate exposures to factors prior to clinical onset from exposures to factors after clinical onset.

In conclusion, this study confirmed that cigarette smoking is significantly associated with higher risk of NSCLC having hypermethylation of $p 16, D A P K$ or $R A R \beta$ promoter, and a general dose-response trend was confirmed. A striking finding was that the interactions between smoking and polymorphism of CYP1A1 or GSTM1 gene increased significantly greater risk of NSCLC with hypermethylation of $p 16, D A P K$ or $R A R \beta$ promoter, suggesting complex pathogenesis of NSCLC should be given top priority in future research.

\section{Acknowledgements}

Grant support: Zhejiang Provincial Natural Science Foundation, China, Project No. R207067, and National Science Fund Committee, China, Project No. 30471427.

We thank all participants for their support from the First Affiliated Hospital of Anhui Medical University in Hefei city and Sir Run Run Shaw Hospital, Zhejiang University School of Medicine, Zhejiang University in Hangzhou, China.

\section{Author details}

'Department of Environmental Medicine or Institute of Environmental Medicine, Zhejiang University School of Medicine, Zhejiang University, 310058 Hangzhou, China. ${ }^{2}$ Department of Cardiothoracic Surgery, Sir Run Run Shaw Hospital, Zhejiang University School of Medicine, Zhejiang University, Hangzhou, 310058 China. ${ }^{3}$ School of Public Health, Anhui Medical University, 230032 Hefei, China. ${ }^{4}$ Institute of Pharmacology, Zhejiang University School of Pharmacology, Zhejiang University, Hangzhou, 310058 China. ${ }^{5}$ Department of Biotechnology, Anhui Medical University, 230032 Hefei, China.

\section{Authors' contributions}

HX gathered clinico-pathological data. CZ, YK, YH and YX were involved in conception of the study, analysis of the data and interpretation of the results. YJ and SX designed the study and wrote the manuscript. All authors approved the final manuscript.

\section{Competing interests}

The authors declare that they have no competing interests.

Received: 20 February 2010 Accepted: 12 August 2010 Published: 12 August 2010

\section{References}

1. Molina JR, Yang P, Cassivi SD, Schild SE, Adjei AA: Non-small cell lung cancer: epidemiology, risk factors, treatment, and survivorship. Mayo Clin Proc 2008, 83:584-594.

2. Herbst RS, Heymach JV, Lippman SM: Lung cancer. N Engl J Med 2008, 359:1367-1380.

3. Lee kM, Kang D, Clapper ML, Ingelman-Sundberg M, Ono-Kihara M, Kiyohara C, et al: CYP1A1, GSTM1, and GSTT1 polymorphisms, smoking, and lung cancer risk in a pooled analysis among Asian populations. Cancer Epidemiol Biomarkers Prev 2008, 17:1120-1126.

4. Risch A, Plass C: Lung cancer epigenetics and genetics. Int J Cancer 2008, 123:1-7.

5. Bartsch H, Nair U, Risch A, Rojas m, Wikman H, Alexandrov K: Genetic polymorphism of CYP gene, alone or in combination, as a risk modifier of tobacco-related cancers. Cancer Epidemiol. Biomarkers Prev 2000, 9:3-28.

6. Schwartz AG, Prysak GM, Bock CH, Cote ML: The molecular epidemiology of lung cancer. Carcinogenesis 2007, 28:507-518.

7. Hecht SS: Cigarette smoking and lung cancer: chemical mechanisms and approaches to prevention. Lancet Oncol 2002, 3:461-469.

8. Adonis M, Martinez V, Marin P, Gil L: CYP1A1 and GSTM1 genetic polymorphisms in lung cancer populations exposed to arsenic in drinking water. Xenobiotica 2005, 35:519-530.

9. Shi X, Zhou S, Wang Z, Zhou Z, Wang Z: CYP1A1 and GSTM1 polymorphisms and lung cancer risk in Chinese populations: A metaanalysis. Lung Cancer 2008, 59:155-163.

10. Belinsky SA, Klinge DM, Dekker JD, Smith MW, Bocklage TJ, Gilliland FD, et al: Gene promoter methylation in plasma and sputum increases with lung cancer risk. Clin Cancer Res 2005, 11:6505-6511.

11. Fujiwara K, Fujimoto N, Tabata M, Nishii K, Matsuo K, Hotta K, et al: Identification of epigenetic aberrant promoter methylation in serum DNA is useful for early detection of lung cancer. Clin Cancer Res 2005, 11:1219-1225.

12. Zochbauer-Muller S, Fong KM, Virmani AK, Geradts J, Gazdar AF, Minna JD: Aberrant promoter methylation of multiple genes in non-small cell lung cancers. Cancer Research 2001, 61:249-255.

13. Doll R, Hill $A B$ : A study the aetiology of cancinoma of the lung. Br Med J 1952, 2:1271-1286. 
14. Yoshino I, Maehara Y: Impact of smoking status on the biological behavior of lung cancer. Surg Today 2007, 37:725-734

15. Cornfield J, Haenszel W, Hammond EC, Lilienfeld AM, Shimkin MB, Wynder EL: Smoking and lung cancer: recent evidence and a discussion of some questions. Intern J Epidemiol 2009, 38:1175-1191.

16. Doll R, Peto R: Mortality in relation to smoking: 20 year's observations on male British doctors. Br Med J 1976, 2:1525-1536.

17. Mattson ME, Pollack ES, Cullen JW: what are the odds that smoking will kill you? Am J Public Health 1987, 77:425-431.

18. Kawajiri K, Nakachi K, Imai K, Yoshii A, Shinoda N, Watanabe J: Identification of genetically high risk individuals to lung cancer by DNA polymorphisms of the cytochrome P4501A1 gene. FEBS Lett 1990, 263:131-133.

19. Vineis P, Veglia F, Benhamou S, Butkiewicz D, Cascorbi I, Clapper ML, et al: CYP1A1 T3801 C polymorphism and lung cancer: a pooled analysis of 2451 cases and 3358 controls. Int I Cancer 2003, 104:650-657.

20. Houlston RS: Glutathione S-transferase M1 status and lung cancer risk: a meta-analysis. Cancer Epidemiol Biomarkers Pre 1999, 8:675-682.

21. Vineis P, Veglia F, Anttila S, Benhamou S, Clapper ML, Dolzan V, et al: CYP1A1, GSTM1 and GSTT1 polymorphisms and lung cancer: a pooled analysis of gene-gene interactions. Biomarkers 2004, 9:298-305.

22. Vineis $P$, Anttila S, Benhamou S, Spinola M, Hirvonen A, Kiyohara C, et al: Evidence of gene gene interactions in lung carcinogenesis in a large pooled analysis. Carcinogenesis 2007, 28:1902-1905.

23. Benhamou S, Lee WJ, Alexandrie AK, Boffetta P, Bouchardy C, Butkiewicz D, et al: Meta- and pooled analysis of the effects of glutathione Stransferase M1 polymorphisms and smoking on lung cancer risk. Carcinogenesis 2002, 23:1343-1350.

24. Butkiewicz D, Cole KJ, Phillips DH, Harris CC, Chorazy M: GSTM1, GSTP1, CYP1A1 and CYP2D6 polymorphisms in lung cancer patients from an environmentally polluted region of Poland: correlation with lung DNA adduct levels. Eur I Cancer Prev 1999, 8:315-323.

25. Belinsky SA: Silencing of genes by promoter hypermethylation: key event in rodent and human lung cancer. Carcinogenesis 2005, 26:1481-1487.

26. Zöchbauer-Müller S, Minna JD, Gazdar AF: Aberrant DNA methylation in lung cancer: biological and clinical implications. Oncologist 2002, 7:451-457.

27. Safar AM, Spencer H, Su X, Coffey M, Cooney CA, Ratnasinghe LD, et al: Methylation profiling of archived non-small cell lung cancer: a promising prognostic system. Clin Cancer Res 2005, 11:4400-4405.

28. Chan EC, Lam SY, Fu KH, Kwong YL: Polymorphisms of the GSTM1, GSTP1 MPO, XRCC1, and NQO1 genes in Chinese patients with non-small cell lung cancers: relationchip with aberrant promoter methylation of the CDKN2A and RAR $\beta$ genes. Cancer Genet Cytogenet 2005, 162:10-20.

\section{Pre-publication history}

The pre-publication history for this paper can be accessed here: http://www.biomedcentral.com/1471-2407/10/422/prepub

doi:10.1186/1471-2407-10-422

Cite this article as: Jin et al:: Combined effects of cigarette smoking, gene polymorphisms and methylations of tumor suppressor genes on non small cell lung cancer: a hospital-based case-control study in China. BMC Cancer 2010 10:422.

\section{Submit your next manuscript to BioMed Central and take full advantage of:}

- Convenient online submission

- Thorough peer review

- No space constraints or color figure charges

- Immediate publication on acceptance

- Inclusion in PubMed, CAS, Scopus and Google Scholar

- Research which is freely available for redistribution

Submit your manuscript at www.biomedcentral.com/submit
Biomed Central 